\title{
Management of Odontoma like Malformation Associated with Unerupted Permanent Maxillary Central Incisor- a Report of Two Cases
}

\author{
Kusum Bharti*, Mridula Goswami, Gyanendra Kumar, Jatinder Dhillon and Deepti Thakkar \\ Department of Pedodontics and Preventive Dentistry, Maulana Azad Institute of Dental Sciences, India
}

Submission: January 26, 2017; Published: February 15, 2017

*Corresponding author: Kusum Bharti, Department of Pedodontics and Preventive Dentistry, Maulana Azad Institute of Dental Sciences, MAMC campus BSZ marg, New Delhi- 110002, India, Tel: +91-959911835; Email: kusumbharti1984@gmail.com

\begin{abstract}
Odontomas are hamartomous lesions or malformations rather than true neoplasm and are frequent cause of impaction, delayed eruption of permanent teeth or retention of primary teeth. This present case report documents the surgical management of two cases of odontoma like malformations causing the impaction of permanent maxillary central incisor. Early diagnoses of such cases are very important to prevent future complications in dental arch development and establishment of occlusion.
\end{abstract}

Keywords: Odontoma; Impaction; Spontaneous eruption

\section{Introduction}

Odontomas are the slow growing, non- aggressive, mixed benign malformations that represents approx. $22 \%$ of all odontogenic tumors of the jaw .They are the developmental anomalies that results from the growth of completely differentiated epithelial and mesenchymal cells that give rise to ameloblasts and odontoblasts [1]. Depending on the histopathological findings, they are classified as Complexion which the dental tissues are well formed but exhibit an amorphous and more or less disorderly arrangement and Compound where dental tissues are arranged in normal orderly pattern, but their size and conformation are altered, giving rise to multiple small teeth like elements called odontoids or denticles [2]. They can be found anywhere in the oral cavity with no sex predilection and are usually diagnosed in second or third decades of life.

The etiology of odontoma remains unknown but is believed to be associated with several factors such as trauma to the primary dentition, any local infection and genetic mutations or even hereditary $[3,4]$. They are generally asymptomatic, often associated with delayed eruption or impaction of permanent teeth or retained primary teeth, expansion of alveolar bone, tooth displacement, regional adenopathies etc. Generally, these malformations are intraosseous, but occasionally they may erupt into the oral cavity. Management of such malformations usually consists of surgical removal and histological examination with osseous recontouring.
The aim of this paper is to describe the features and management of radiographically diagnosed two cases of odontomas like malformations associated with unerupted maxillary central incisor.

\section{Case Report-1}

A 14 year old male patient reported to the Department of Pedodontics \& Preventive Dentistry, with a chief complaint of unerupted tooth in the left upper front teeth region. Parents gave the history of trauma to the anterior region of the face of a child at the age of six. No family and medical history was significant.

On clinical examination, there were no significant extra oral findings whereas intraoral examination revealed permanent dentition with a retained grossly decayed tooth 61 associated with swelling over the apical region of 22 . The contra lateral tooth 11 had already been erupted in the oral cavity. Radiographic examination included Orthopantomogram (OPG) that showed the presence of well defined, irregular radiopaque lesion with the dimension approx. $1.1 \mathrm{~cm} \times 1.9 \mathrm{~cm} \times 1.4 \mathrm{~cm}$ respectively associated with unerupted 21. Cone Beam Computed Tomography (CBCT) scan showed that the lesion had well defined irregular hyperdensity similar to enamel and dentin arranged in a haphazard pattern. Clinical and radiographic findings suggested of it as a case of Complex Composite Odontoma diagnosed provisionally (Figure 1). 


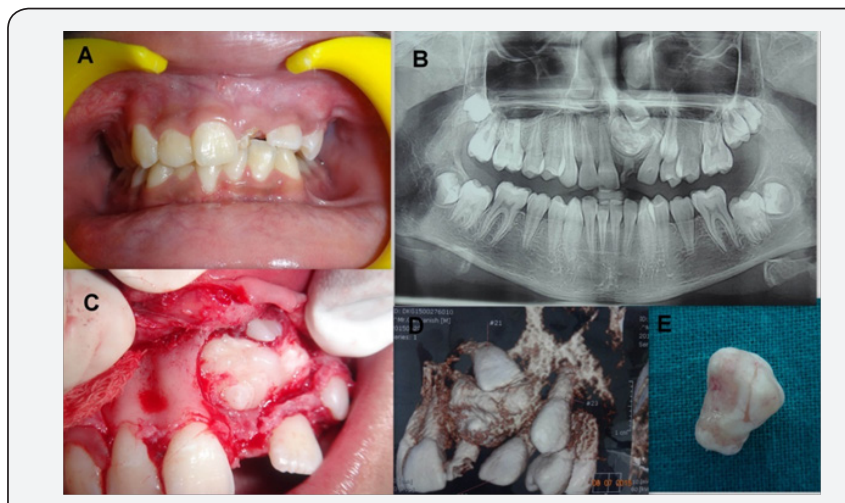

Figure 1: Clinical and radiographical photographs of patient 1.

a. Intraoral view showing grossly decayed tooth 61 \& swelling (arrow) over the apical region of tooth 22.

b. OPG showing radiopaque mass (encircled) in relation to the unerupted crown of tooth 21.

c. Hard, calcified lesion seen after reflection of full thickness mucoperiosteal flap.

d. CBCT scan showing the well defined, irregular lesion similar to enamel and dentin arranged in haphazard pattern suggestive of Complex odontoma.

e. Complex odontoma like malformation after removal from the site.

\section{Case Report-2}

A 12 year old female patient reported with a chief complaint of unerupted tooth in the maxillary anterior teeth region. There was a history of trauma to the anterior region of teeth revealed by parents. Patient's family and medical history was noncontributory.

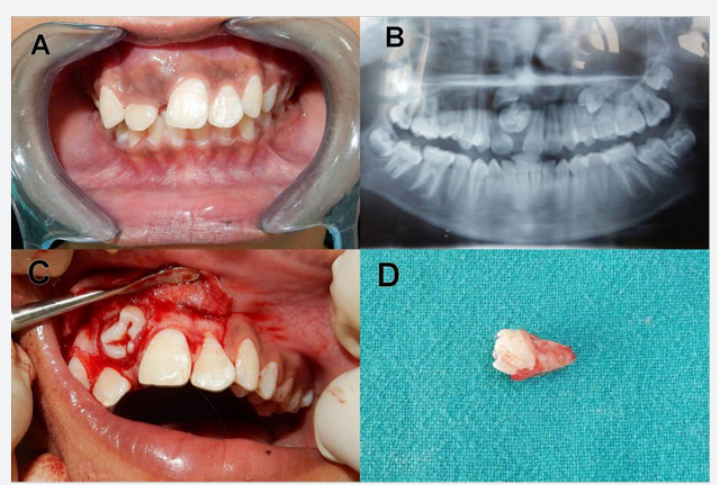

Figure 2: Clinical and radiographical photographs of patient 2. a. Intraoral view showing swelling (arrow) over the apical region of tooth 12 .

b. OPG showing radiopaque mass (encircled) in relation to the unerupted crown of tooth 11.

c. Full thickness mucoperiosteal flap has been reflected and hard calcified lesion seen in relation to tooth.

d. After surgical removal, a tooth like malformation seen that has orderly arrangement of enamel and dentin suggestive of Compound odontoma.

Clinical examination showed a presence of intraoral swelling between the apical root region of 12 and 21. Radiographic examination revealed a condensed radiopaque mass in close proximity to the crown of unerupted 11 on OPG x-ray (Figure 2).

In both the cases, surgical removal of odontoma like malformation was planned. After administering 2\% local anesthesia, a mucoperiosteal flap on the labial surface was reflected. The layer of bone overlying the labial surface was removed and the calcified mass was exposed. The mass was removed cautiously without disturbing the surrounding tissues and was kept in $10 \%$ formalin for histopathological examination. Curettage was done in the area to remove any remnants followed by gentle irrigation with saline solution. The flap was replaced and sutured back in position for uneventful healing. Postoperative oral and written

Instructions specifically related to the maintenance of an appropriate oral hygiene, ingestion of cold and soft meals, refraining from physical exercise during 48 hours, and management of pain were given to the patient's care giver. To assess the eruption of unerupted tooth and to examine the recurrence of odontoma, routine clinical and radiographic follow ups once in every three months was advised to parents.

\section{Discussion}

Any kind of insult or injury to the primary dentition during the developmental stages of the succedaneous tooth may obscure its future growth due to the close approximation between the apices of primary teeth and the buds of permanent teeth. Such insult can be manifested and could lead to various tooth malformations such as enamel hypoplasia, root and crown dilaceration and less frequently odontoma [1]. Radiographically, these lesions manifest as a radiopaque solid mass with occasional nodular elements, and surrounded by a fine radio transparent zone. They are usually associated with retention of primary teeth or abnormalities in tooth position, such as tipping or displacement of adjacent teeth and impaction or delayed eruption of a permanent tooth [2].

In the present case report, the odontoma like malformation was the cause of non eruption of a permanent successor and are also associated with the trauma to the primary dentition at an early age. If diagnosed at initial stages, treatment can be provided effectively to enhance esthetics, functions and structural balance in developing dentition.

The treatment options for such type of lesions comprises of surgical removal by conservative approach. Spontaneous eruption of the impacted tooth after removal of the obstruction like odontoma has been reported by many authors [3,5]. A less conservative approach has also been advocated with exposure of the unerupted tooth at the time of surgery and placement of bonded attachment for orthodontic traction to facilitate rapid eruption if the tooth does not erupt after the recommended follow up time period [1].

i. This approach however may result in inadequate gingival tissue attachment, poor gingival margin and discrepancy between gingival margins of the exposed tooth and its neighboring teeth [2]. 
ii. Hence, in the present case report, a more conservative approach has been planned for removal of odontoma and its fibrous capsule. Recall follow-up visits had been advised to parents every 3 months for monitoring the spontaneous eruption of impacted permanent maxillary central incisors in both the cases. Since, odontomas represents a fairly greater [6-8].

\section{Conclusion}

The present case report focuses and provides information about the clinical manifestations, diagnosis and management of such developmental malformations and the future complications associated with their presence. Therefore, it is mandatory for the dental practitioners to be knowledgeable about the appearance and complications associated with such developmental abnormalities so that they can diagnose at an initial age and can be managed effectively.

\section{References}

1. Bhaskar SN (1968) Oral pathology in the dental office: survey of 20,575 biopsy specimens. J Am Dent Assoc 76(4): 761-766.
2. Budnick SD (1976) Compound and complex odontomas. Oral Surg Oral Med Oral Pathol 42(4): 501-506.

3. Hidalgo-Sanchez O, Leco-Berrocavl MI, Martinez-Gonzale JM (2008) Metaanalysis of the epidemiology and clinical manifestations of odontomas. Med Oral Patol Oral Cir Bucal 13(110): E730-734.

4. Owens BM, Schuman NJ, Mincer HH, Turner JE, Oliver FM (1997) Dental odontomas: a retrospective study of 104 cases. J Clin Pediatr Dent 21(3): 261-264.

5. Hattab FN, Yassin OM, Rawashdeh MA (1994) Supernumerary teeth: Report of three cases and review of the literature. J Dent Child 61(5-6): 382-393.

6. Ferrer Ramirez MJ, Silvestre Donat FJ, Estelles Ferriol E, Grau Garcia Moreno D, Lopez Martinez R (2001)Recurrent infection of a complex odontoma following eruption in the mouth. Med Oral 6(4): 269-275.

7. Kaugars GE, Miller ME, Abbey LM (1989) Odontomas. Oral Surg Oral Med Oral Pathol 67: 172-176.

8. Batra P, Duggal R, Kharbanda OP, Prakash H (2004) Orthodontic Treatment of impacted anterior teeth due to odontomas: A report of two cases. J Clin Pediatr Dent 28(4): 289-294.

\begin{tabular}{|l|}
\hline \multicolumn{1}{|c|}{ Your next submission with Juniper Publishers } \\
will reach you the below assets \\
- Quality Editorial service \\
- Swift Peer Review \\
- Reprints availability \\
- E-prints Service \\
- Manuscript Podcast for convenient understanding \\
- Global attainment for your research \\
- Manuscript accessibility in different formats \\
( Pdf, E-pub, Full Text, Audio) \\
- Unceasing customer service \\
Track the below URL for one-step submission \\
https://juniperpublishers.com/online-submission.php
\end{tabular}

